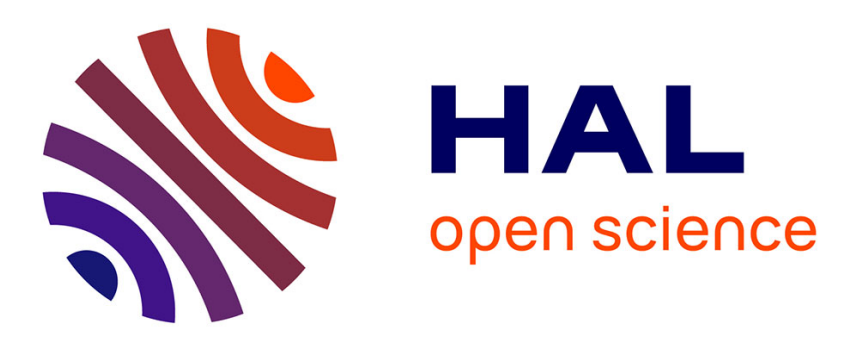

\title{
Impact of Textile on Electromagnetic Power and Heating in Near-Surface Tissues at $26 \mathrm{GHz}$ and $60 \mathrm{GHz}$ \\ Giulia Sacco, Stefano Pisa, Maxim Zhadobov
}

\section{To cite this version:}

Giulia Sacco, Stefano Pisa, Maxim Zhadobov. Impact of Textile on Electromagnetic Power and Heating in Near-Surface Tissues at $26 \mathrm{GHz}$ and $60 \mathrm{GHz}$. IEEE Journal of Electromagnetics, RF and Microwaves in Medicine and Biology, 2021, 5 (3), pp.262-268. 10.1109/JERM.2020.3042390 . hal-03137416

\section{HAL Id: hal-03137416 https://hal-univ-rennes1.archives-ouvertes.fr/hal-03137416}

Submitted on 10 Feb 2021

HAL is a multi-disciplinary open access archive for the deposit and dissemination of scientific research documents, whether they are published or not. The documents may come from teaching and research institutions in France or abroad, or from public or private research centers.
L'archive ouverte pluridisciplinaire HAL, est destinée au dépôt et à la diffusion de documents scientifiques de niveau recherche, publiés ou non, émanant des établissements d'enseignement et de recherche français ou étrangers, des laboratoires publics ou privés. 


\title{
Impact of Textile on Electromagnetic Power and Heating in Near-Surface Tissues at $26 \mathrm{GHz}$ and $60 \mathrm{GHz}$
}

\author{
Giulia Sacco, Student Member, IEEE, Stefano Pisa, Senior Member, IEEE \\ and Maxim Zhadobov, Senior Member, IEEE
}

\section{Exposure Scenario}

Near-Surface Tissue Model
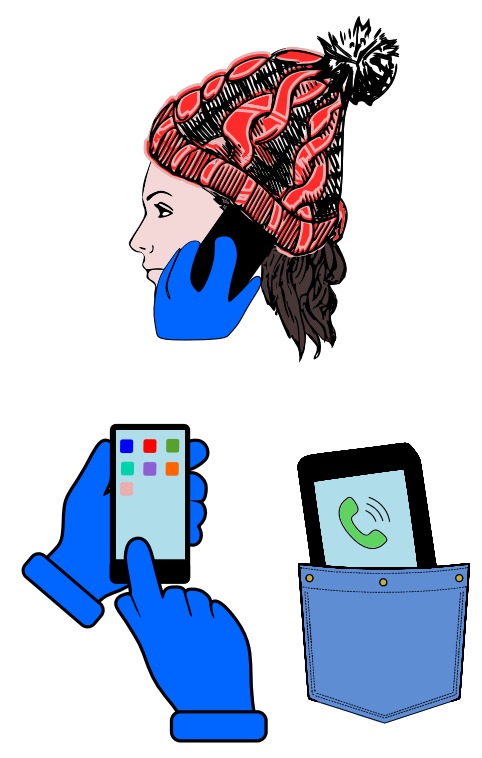

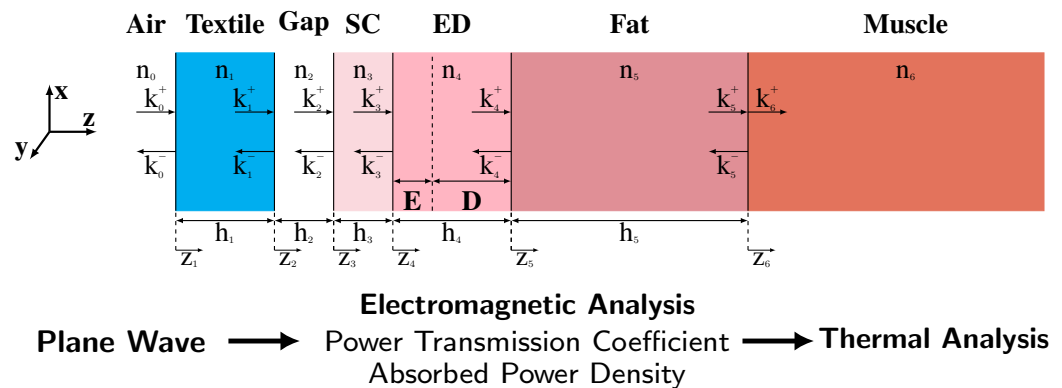

Textile in Contact with Skin Textile in Proximity of Skin
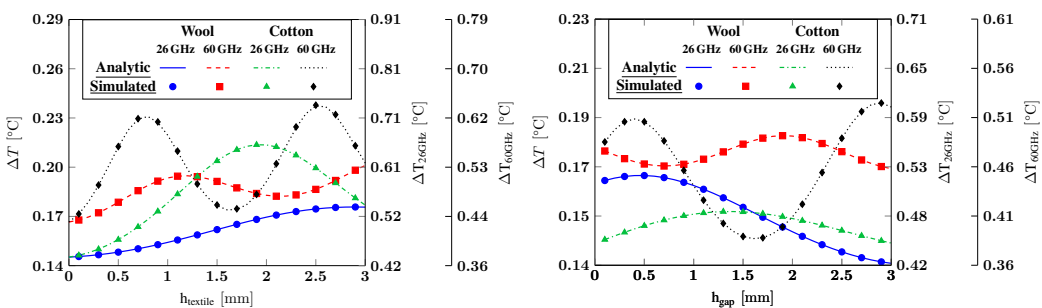

The presence of a textile in contact or in proximity with skin modifies the electromagnetic power deposition and heating in the tissues depending on the thicknesses and permittivity.

\section{Take-Home Messages}

- This study provides, for the first time, a detailed quantitative analysis of the electromagnetic power absorption and temperature elevation in presence of a textile at $26 \mathrm{GHz}$ and $60 \mathrm{GHz}$, frequencies upcoming for 5 th generation $(5 \mathrm{G})$ and next generations of wireless communications systems.

- We demonstrate that a textile in contact or in proximity of skin impacts the power deposition and the consequent temperature elevation; in particular, cotton and wool in contact with skin increase the absorbed power density up to $41.5 \%$ at $26 \mathrm{GHz}$ and $34.4 \%$ at $60 \mathrm{GHz}$.

- The interest of this study is to evaluate the exposure in the upcoming $5 \mathrm{G}$ bands in the scenarii involving interaction of electromagnetic fields in presence of a textile layer (e.g. usage of a tablet lying on the user's legs or of radiating devices during wintertime, when wearing hats or gloves).

- We analysed and quantified, for the first time, the power absorption and temperature elevation at $26 \mathrm{GHz}$ and $60 \mathrm{GHz}$ in presence of some of the most common textiles used for clothes (i.e. cotton and wool).

- We demonstrate that with the textile in direct contact with skin the temperature rise increases compared to the bare skin by up to $52 \%$ at $26 \mathrm{GHz}$ and $46 \%$ at $60 \mathrm{GHz}$ and that, with an air gap and for typical textile thicknesses, the variation ranges from $-3.5 \%$ to $20.6 \%$ and from $-11.1 \%$ to $20.9 \%$ at $26 \mathrm{GHz}$ and $60 \mathrm{GHz}$, respectively. 


\title{
Impact of Textile on Electromagnetic Power and Heating in Near-Surface Tissues at $26 \mathrm{GHz}$ and $60 \mathrm{GHz}$
}

\author{
Giulia Sacco, Student Member, IEEE, Stefano Pisa, Senior Member, IEEE \\ and Maxim Zhadobov, Senior Member, IEEE
}

\begin{abstract}
With the development of 5th generation (5G) networks the operating frequencies have been progressively expanding towards millimeter waves (MMW). In some exposure scenarii, presence of textiles impacts the interaction of the electromagnetic field radiated by wireless devices with human tissues. We investigate the impact of a textile layer in contact or in proximity of skin on the power transmission coefficient, absorbed power density and temperature rise using a near-surface tissue model at 26 GHz and $60 \mathrm{GHz}$. Cotton and wool are considered as representative textiles. Our results demonstrate that the textile in contact with skin increases the absorbed power density up to $41.5 \%$ at $26 \mathrm{GHz}$ and $34.4 \%$ at $60 \mathrm{GHz}$. The presence of an air gap between a textile and skin modifies the electromagnetic power deposition in the tissues depending on the thicknesses and permittivity. The temperature rise increases compared to the bare skin by up to $52 \%$ at $26 \mathrm{GHz}$ and $46 \%$ at $60 \mathrm{GHz}$ with the textile in direct contact with skin. With an air gap, for typical textile thicknesses, the temperature variations range from $-3.5 \%$ to $20.6 \%$ and from $-11.1 \%$ to $20.9 \%$ at $26 \mathrm{GHz}$ and $60 \mathrm{GHz}$, respectively.
\end{abstract}

Keywords-5G, millimeter waves (MMW), textile, electromagnetic and thermal dosimetry.

\section{INTRODUCTION}

$\mathbf{R}$ ECENT advances in millimeter waves (MMW) technologies together with the growing need for high data rates and secure communications are leading to the fast development of 5 th generation $(5 \mathrm{G})$ mobile networks, whose operating frequencies have been progressively shifting towards the MMW band [1], [2].

Exposure guidelines have been defined by the International Commission on Non-ionizing Radiation Protection (ICNIRP) and International Electrical and Electronics Engineers (IEEE) [3], [4]. In the $6 \mathrm{GHz}-300 \mathrm{GHz}$ range, exposure limits are expressed in terms of the incident power density (IPD), whose value for whole body exposure should be limited to $10 \mathrm{~W} \mathrm{~m}^{-2}$ and $50 \mathrm{~W} \mathrm{~m}^{-2}$ (averaged over $30 \mathrm{~min}$ ) for unrestricted environment/general public exposure and restricted environment/occupational exposure, respectively. For local exposures, frequency-dependent limits are recommended, i.e. the IPD should not exceed $55 f_{G}^{-0.177}\left(f_{G}\right.$ : frequency in $\mathrm{GHz}$ ) for unrestricted environment/general public exposure and $275 f_{G}^{-0.177}$ or $274.8 f_{G}^{-0.177}$ for restricted environment/occupational exposure according to ICNIRP and IEEE, respectively [3], [4]. The IPD values should be averaged over $4 \mathrm{~cm}^{2}$ and $6 \mathrm{~min}$. To account for a smaller beam diameter above $30 \mathrm{GHz}$, the IPD averaged over $1 \mathrm{~cm}^{2}$ is allowed to exceed the limit by a factor of 2 .

G. Sacco is with the Department of Information Engineering, Electronics and Telecommunications, Sapienza University of Rome, 00184 Rome, Italy and with Univ Rennes, CNRS, IETR (Institut d'Électronique et des Technologies du numéRique), UMR 6164, F-35000, Rennes, France (email: giulia.sacco.it@gmail.com).

S. Pisa is with the Department of Information Engineering, Electronics and Telecommunications, Sapienza University of Rome, 00184 Rome, Italy (e-mail: stefano.pisa@uniroma1.it).

M. Zhadobov is with Univ Rennes, CNRS, IETR (Institut d'Électronique et des Technologies du numéRique), UMR 6164, F-35000, Rennes, France (e-mail: maxim.zhadobov@univ-rennes1.fr).
Recent studies investigated the exposure under realistic conditions with the user terminal close to the head [5], focusing on thermoregulation [6] or on the impact of pulsed fields [7], [8]. At MMW, the interaction between human tissues and the incident electromagnetic field in terms of the deposited power and resulting heating was investigated in several works [9]-[11]. All these studies consider the electromagnetic field impinging directly on the bare skin. However, in some use cases, clothing can modify the electromagnetic power absorption in tissues and resulting temperature rise. A representative example is when, during a call, the user places the phone in his pocket while using a headphone. Other possible scenarii include the usage of a tablet lying on the user's legs or of radiating devices during wintertime, when wearing hats or gloves. In all these conditions, the presence of textiles is to be taken into account for accurate dosimetry.

Several studies considered the impact of clothes at MMW [12]-[15]. In particular, [15] investigated how the presence of a textile layer affects the power transmission coefficient, demonstrating that the clothing can act as an impedance transformer and increase the absorption. Body-centric propagation in the context of the body area networks at $60 \mathrm{GHz}$ was investigated in [12]-[14] in term of the path gain. These studies analysed the power transmission coefficient in presence of a textile on simplified model of skin, without considering the deposited electromagnetic power and the resulting heating, which may also be impacted by the subcutaneous fat and muscle [11].

The main purpose of this study is to investigate analytically and numerically the electromagnetic power deposition and consequent temperature rise in a near-surface multilayer tissue model considering the impact of a textile layer on or in vicinity of skin. Cotton and wool, two textile materials typically used for clothes realization, are employed as representative models. The analysis is performed at $26 \mathrm{GHz}$ and $60 \mathrm{GHz}$, frequencies upcoming for $5 \mathrm{G}$ and future generations of wireless technolo- 


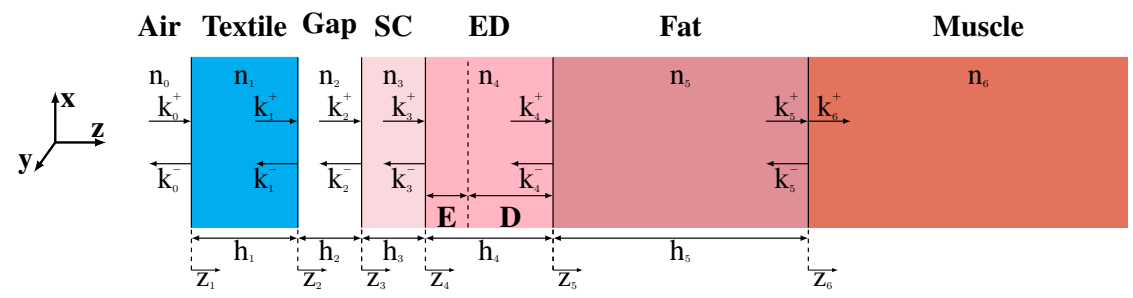

Figure 1: Model used for calculation of absorbed power and temperature rise.

Table I: Permittivity, thermal conductivity, mass density, and blood perfusion of the model layers.

\begin{tabular}{c|c|c|c|c|c}
\hline Layer & \multicolumn{2}{|c|}{$\varepsilon^{*}$} & $\lambda_{i}\left(\mathbf{W ~ m ~ m}^{\mathbf{- 1}}{ }^{\circ} \mathbf{C}^{\mathbf{- 1}}\right)$ & $\rho_{i}\left(\mathbf{k g ~ m}^{-\mathbf{3}}\right)$ & $B_{i}\left(\mathbf{W ~ m}^{\mathbf{- 3}}{ }^{\circ} \mathbf{C}^{\mathbf{- 1}}\right)$ \\
\hline \multirow{2}{*}{ stratum corneum (SC) } & $26 \mathrm{GHz}$ & $60 \mathrm{GHz}$ & & & \\
Viable epidermis & $3.62-j 0.74$ & $3.15-j 0.50$ & 0.37 & 1500 & 0 \\
Dermis & $17.71-j 16.87$ & $7.98-j 10.90$ & 0.37 & 1109 & 0 \\
Fat & $3.76-j 16.87$ & $7.98-j 10.90$ & 0.37 & 1109 & 7440 \\
Muscle & $25.85-j 21.84$ & $3.13-j 0.84$ & 0.21 & 911 & 1900 \\
Air & \multicolumn{2}{|c|}{$12.86-j 15.83$} & 0.49 & 1090 & 2550 \\
Cotton & $2-j 0.04$ & 0.027 & 1.13 & 0 \\
Wool & $1.22-j 0.036$ & 0.071 & 500 & 0 \\
\hline
\end{tabular}

gies. For the sake of simplicity and brevity, we refer to $26 \mathrm{GHz}$ as MMW, since at this frequency the interactions between the human tissues and electromagnetic fields are similar to the ones at lower frequencies of the MMW band.

\section{Materials AND Methods}

A near-surface tissue model illuminated by a normal impinging plane wave is used to assess the electromagnetic power deposition and resulting heating in presence of a textile (Figure 1). Two configurations are considered: (1) clothes in contact with skin (Figure 1 with $h_{2}=0 \mathrm{~mm}$ ), and (2) clothes in proximity of the biological tissues in presence of an air gap between the textile material and skin $\left(h_{2}>0 \mathrm{~mm}\right)$. The tissue model consists of 4 layers: SC, viable epidermis and dermis (ED), fat and muscle. The SC is the uppermost layer of the epidermis and is characterized by a low water content (roughly $2 \%$ by weight [11]) and typical thickness of $10 \mu \mathrm{m}-20 \mu \mathrm{m}$ [16]. The ED layer is composed of the remaining portion of the epidermis and dermis. The latter, has almost the same water content as viable epidermis and therefore, from the electromagnetic point of view, can be considered as the same layer. However, since only dermis contains blood vessels, epidermis and dermis are considered as two separate layers for the thermal analysis. As at MMW the penetration depth is limited to skin, fat and muscle layers almost do not affect the electromagnetic field distribution but they impact the temperature rise.

The complex permittivity $\varepsilon^{*}$ of the considered model is reported in Table I. The permittivity of SC is taken from [11], while the ones of the remaining layers (ED, fat and muscle) correspond to the dry skin, not-infiltrated fat and muscle in [17]. Cotton and wool, with the thickness ranging from $0 \mathrm{~mm}$ to $3 \mathrm{~mm}$ (typical values are $0.2 \mathrm{~mm}$ for cotton and $2 \mathrm{~mm}$ for wool [14]), have been considered as representative textiles. Their permittivity measured at $60 \mathrm{GHz}$ was reported in [14]. The textiles are assumed to be non-dispersive in the frequency range considered in this study [18], [19]. The power transmission coefficient, absorbed (or epithelial) power density [3], [4], referred hereafter as PD, and maximal temperature elevation in the skin layer were analytically calculated and numerically computed considering the IPD limits for whole body exposure and the frequency dependent ones $\left(30.90 \mathrm{~W} \mathrm{~m}^{-2}\right.$ and $26.65 \mathrm{~W} \mathrm{~m}^{-2}$ at $26 \mathrm{GHz}$ and $60 \mathrm{GHz}$, respectively). The power transmission coefficient is computed at the interface between the textile and the surrounding environment as $|T|^{2}=1-\left|R_{0}\right|^{2}$, where $R_{0}$ is the reflection coefficient between air and the textile layer. The PD is defined as the power flow through the SC per unit area on the body surface [3], [4]. Note that for the considered planar model and continuous plane-wave illumination, spatial or temporal averaging would not change the results since the PD is invariant in time and uniform in the $\mathrm{x}$ and $\mathrm{y}$ directions.

\section{A. Analytical Model}

The electromagnetic problem for a multilayer model excited by a plane wave can be solved analytically. Hypothesizing a normal wave incidence, the wave vector is directed along $\mathrm{z}$, while the electric field is along $\mathrm{x}$ axis. Assuming that the power transmitted to the muscle layer from fat is entirely dissipated, the total electric field $\boldsymbol{E}_{i}\left(z_{i}\right)$ in the $\mathrm{i}_{\text {th }}$ layer is given by

$$
\begin{aligned}
& \boldsymbol{E}_{i}\left(z_{i}\right)=\boldsymbol{E}_{0}^{+} \times \\
& \prod_{n=0}^{j-1} \frac{1}{1+r_{n}} e^{j k_{n+1} h_{n+1}}\left(1+r_{n} R_{n+1} e^{-j 2 k_{n+1} h_{n+1}}\right)
\end{aligned}
$$

where $R_{i}=E_{i}^{-} / E_{i}^{+}$is the reflection coefficient at the $i_{t h}$ interface, $r_{i}=\left(n_{i}-n_{i+1}\right) /\left(n_{i}+n_{i+1}\right)$ is a function of $n_{i}=$ $\sqrt{\varepsilon_{i}^{*}}$, and $k_{i}$ is the wave number in the $i_{t h}$ layer. For the textile in direct contact with skin, the subscripts exceeding 2 are reduced by 1 . From the root mean square value of the 
electric field $E_{i_{r m s}}$, conductivity $\sigma_{i}$ and density $\rho_{i}$, the specific absorption rate (SAR) is calculated as:

$$
S A R_{i}=\frac{\sigma_{i}\left|E_{i_{r m s}}\right|^{2}}{\rho_{i}} .
$$

Using SAR as a heat source, the temperature rise can be computed from the bioheat equation

$$
\lambda_{i} \frac{d^{2} T_{i}\left(z_{i}\right)}{d z_{i}^{2}}=B_{i}\left(T_{i}\left(z_{i}\right)-T_{\text {blood }}\right)-\rho_{i} S A R_{i}\left(z_{i}\right),
$$

where $T_{\text {blood }}=37^{\circ} \mathrm{C}$ is the blood temperature, $\lambda_{i}$ is the thermal conductivity of the $i_{t h}$ layer, $B_{i}=B F_{i} \rho_{b} C_{b}$ is the blood perfusion that depends on the volumetric blood flow rate of the $i_{t h}$ layer $B F_{i}$, on the blood density $\rho_{b}=1050 \mathrm{~kg} \mathrm{~m}^{-3}$ and on the heat capacity $C_{b}=3617 \mathrm{~J} \mathrm{~kg}^{-1}{ }^{\circ} \mathrm{C}^{-1}$ [20]. Metabolic heat was neglected since the temperature rise rather than its absolute value was considered. The thermal conductivity, mass density, and blood perfusion are summarized in Table I. The thermal conductivities and densities of the ED, fat, and muscle are taken from [20]. The thermal conductivity, blood flow and mass density for the biological tissues are taken from [9]. The thermal conductivity of the textile materials are from [21]. The mass density of the textiles $\rho_{\text {textile }}=500 \mathrm{~kg} \mathrm{~m}^{-3}$ represents a typical value [21], [22].

The temperature distribution in the tissue layers is obtained solving Equation (3). In absence of an air gap between textile and skin $\left(h_{2}=0 \mathrm{~mm}\right.$ in Figure 1$)$, the continuity of the temperature and heat flux at the interface between two intermediate layers is imposed:

$$
\begin{aligned}
T_{i}\left(h_{i}\right) & =T_{i+1}(0) \\
-\left.\lambda_{i} \frac{d T_{i}\left(z_{i}\right)}{d z_{i}}\right|_{z_{i}=h_{i}} & =-\left.\lambda_{i+1} \frac{d T_{i+1}\left(z_{i+1}\right)}{d z_{i+1}}\right|_{z_{i+1}=0},
\end{aligned}
$$

while the boundary conditions for the deepest and the uppermost layer are

$$
\begin{aligned}
T_{\text {last }}(\infty) & =T_{\text {blood }} \\
-\left.\frac{d T_{1}\left(z_{1}\right)}{d z_{1}}\right|_{z_{1}=0} & =\frac{h}{\lambda_{1}}\left(T_{1}(0)-T_{\text {air }}\right),
\end{aligned}
$$

respectively. The heat transfer coefficient $h$ between the textile and surrounding environment is set to $5 \mathrm{~W} \mathrm{~m}^{-1}{ }^{\circ} \mathrm{C}^{-1}$ [23]. The study is performed at the ambient temperature $T_{\text {air }}=20^{\circ} \mathrm{C}$. The same boundary conditions apply to the configuration with an air gap between the textile and skin, except for the interface 1 and 2. The presence of an air gap between the textile and skin can be treated as a closed enclosure [16], [24], [25], and the heat flux at its boundaries can be described as

$$
\begin{aligned}
&-\left.\lambda_{1} \frac{d T_{1}\left(z_{1}\right)}{d z_{1}}\right|_{z_{1}=h_{\text {Textile }}}=N u \frac{\lambda_{\text {air }}}{h_{\text {gap }}}\left(T_{3}(0)-T_{1}\left(h_{\text {textile }}\right)\right), \\
&-\left.\lambda_{3} \frac{d T_{3}\left(z_{3}\right)}{d z_{3}}\right|_{z_{3}=0}=N u \frac{\lambda_{\text {air }}}{h_{\text {gap }}}\left(T_{3}(0)-T_{1}\left(h_{\text {textile }}\right)\right),
\end{aligned}
$$

where $\mathrm{Nu}$ is the Nusselt number, $h_{\text {gap }}$ is the gap thickness and $\lambda_{\text {air }}$ is the air thermal conductivity [26] at $37^{\circ} \mathrm{C}$. Below the exposure limits [3], [4], the temperature rise in the human

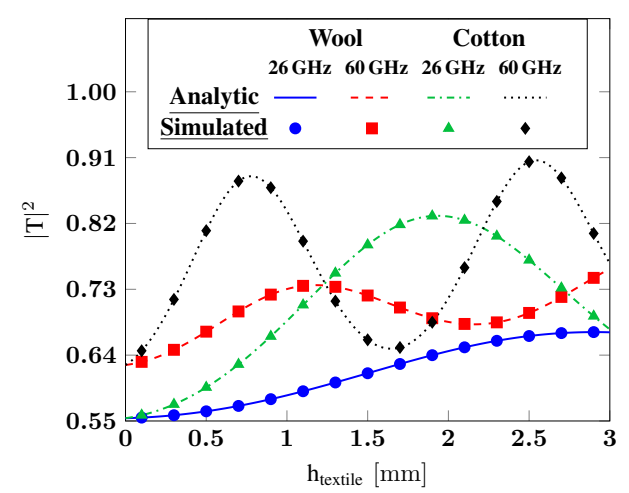

Figure 2: Power transmission coefficient at $26 \mathrm{GHz}$ and $60 \mathrm{GHz}$ in presence of a textile layer in contact with skin.

tissues is expected not to exceed $1{ }^{\circ} \mathrm{C}$, and therefore convection inside the air gap is neglected. In this case, the heat exchange in the air gap is reduced to conductivity and $N u=1$ [27].

\section{B. Numerical Model}

A stratified model analogous to the one presented in Figure 1 was simulated using a finite element method. The layers properties are the same as the ones used in the analytical model, except for the muscle thickness, supposed infinite in the analytical analysis and set to $60 \mathrm{~mm}$ in simulations. A perfect electric conductor was used at the boundaries perpendicular to the $\boldsymbol{E}$ field (y direction) and Floquet periodic boundary conditions in the $\mathrm{x}$ direction. An excitation and an observation port were located in the $\mathrm{z}$ direction at the top and bottom boundaries, respectively. For the thermal analysis, adiabatic boundaries were imposed in the $\mathrm{x}$ and $\mathrm{y}$ directions, while the temperature at the deepest extremity of the muscle was set to $37^{\circ} \mathrm{C}$. At the interface between the textile and air the same condition as in Equation (7) was imposed.

\section{RESULTS}

\section{A. Power Transmission Coefficient}

The two parameters affecting the transmission at the air/textile interface when the textile is in direct contact with skin are its thickness and permittivity. Figure 2 reports the power transmission coefficient in presence of a cotton or wool. The transmission increases compared to the air/skin interface without textile. An oscillatory behaviour is observed since, at certain thicknesses, the textile acts as a matching layer (e.g. for cotton $1.93 \mathrm{~mm}$ and $2.54 \mathrm{~mm}$ at $26 \mathrm{GHz}$ and $60 \mathrm{GHz}$, respectively). The absorbed power is the highest when the textile has a thickness close to $(2 n+1) \lambda / 4$, with $\lambda$ the wavelength in the material and $n$ an integer. In particular, $\lambda / 4$ at $26 \mathrm{GHz}$ corresponds to $2.61 \mathrm{~mm}$ for wool and to $2.04 \mathrm{~mm}$ for cotton. At $60 \mathrm{GHz}$, it is equal to $1.13 \mathrm{~mm}$ and $0.88 \mathrm{~mm}$ for wool and cotton, respectively. The maximum power transmission coefficient does not occur exactly at these thicknesses. This can be attributed to the fact that, contrary to an ideal quarterwave impedance transformer, the impedance of the textile is fixed by the material and is in general different from the one assuring the optimal matching conditions. Depending on the

\section{ACCEPTED MANUSCRIPT}




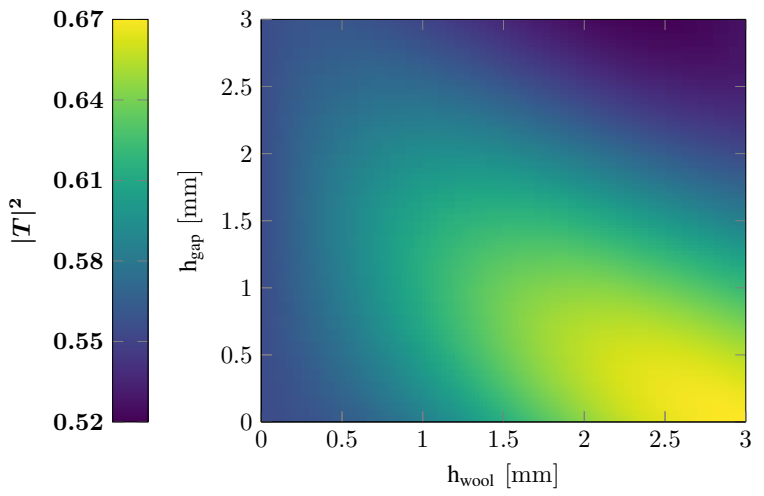

(a)

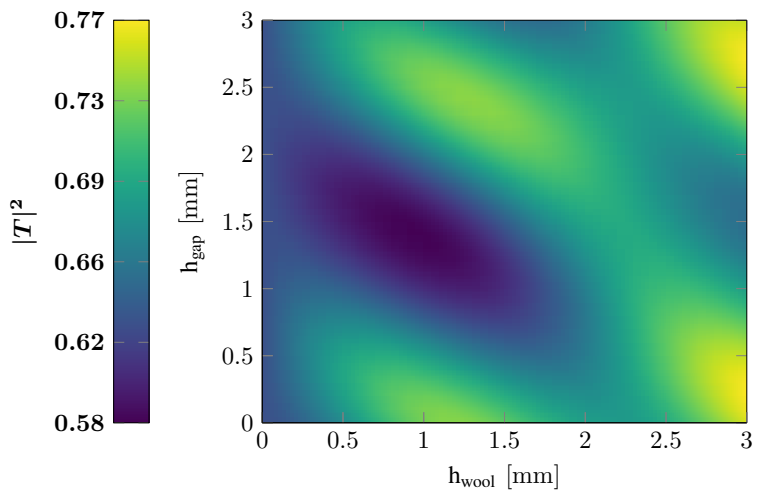

(c)

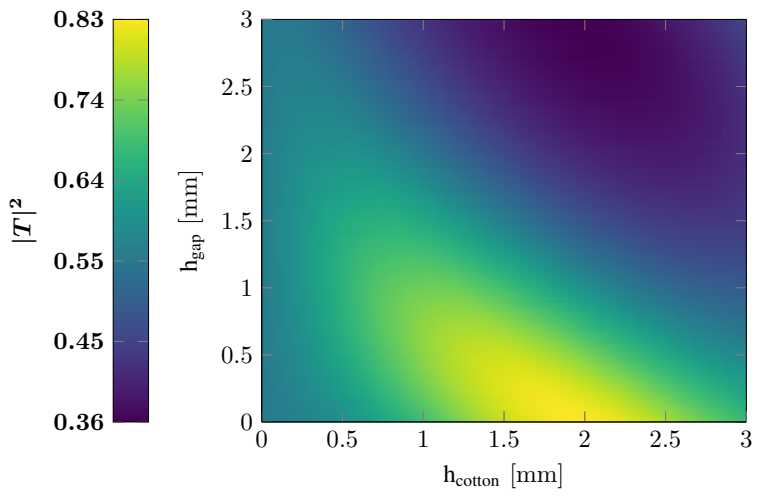

(b)
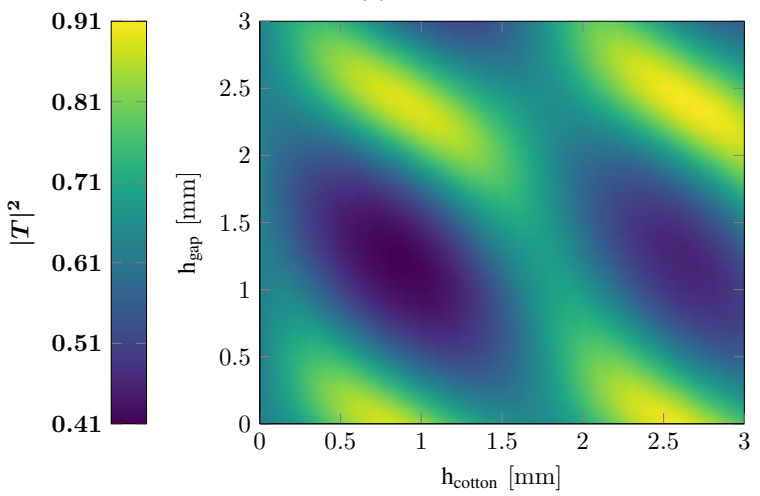

(d)

Figure 3: Power transmission coefficient at $26 \mathrm{GHz}$ ((a) with wool and (b) with cotton), and at $60 \mathrm{GHz}((\mathrm{c})$ with wool and (d) with cotton).

textile thickness, at $26 \mathrm{GHz}$ the power transmission coefficient varies from about $55 \%\left(h_{2}=0 \mathrm{~mm}\right)$ to $67 \%\left(h_{2}=2.91 \mathrm{~mm}\right)$ for wool and from $55 \%$ to $83 \%\left(h_{2}=1.93 \mathrm{~mm}\right)$ for cotton. At $60 \mathrm{GHz}$, it is between $63 \%\left(h_{2}=0 \mathrm{~mm}\right)$ and $76 \%\left(h_{2}=3 \mathrm{~mm}\right)$ for wool and between $63 \%$ and $91 \%$ $\left(h_{2}=2.54 \mathrm{~mm}\right)$ for cotton.

When the textile is separated from skin by an air gap, concurrently with the textile thickness and permittivity, the air gap thickness impacts the power transmission coefficient. A parametric study was performed to analyse the sensitivity of the power transmission coefficient to the textile and air gap thicknesses in presence of wool and cotton (Figure 3). At $26 \mathrm{GHz}$, the maximum transmission is observed for $h_{\text {gap }}=$ $0 \mathrm{~mm}, h_{\text {wool }}=2.91 \mathrm{~mm}$ and $h_{\text {gap }}=0 \mathrm{~mm}, h_{\text {cotton }}=$ $1.93 \mathrm{~mm}$. At $60 \mathrm{GHz}$, for each textile, local maxima appear for four different combinations of $h_{\text {gap }}$ and $h_{\text {textile. }}$. For wool the peak transmission (77\%) occurs in two different conditions: $h_{\text {gap }}=0.22 \mathrm{~mm}, h_{\text {wool }}=3 \mathrm{~mm}$ and $h_{\text {gap }}=2.72 \mathrm{~mm}$, $h_{\text {wool }}=3 \mathrm{~mm}$. For cotton, four different combinations of textile and air gap thickness $\left(h_{\text {gap }}=0 \mathrm{~mm}\right.$ and $h_{\text {cotton }}=$ $0.78 \mathrm{~mm}$ or $h_{\text {cotton }}=2.54 \mathrm{~mm}$, and $h_{\text {gap }}=2.39 \mathrm{~mm}$ and $h_{\text {cotton }}=0.90 \mathrm{~mm}$ or $h_{\text {cotton }}=2.66 \mathrm{~mm}$ ) assure the highest power transmission coefficient (91\%). Note that, as the reflection coefficient at the air/skin interface decreases due to the presence of a textile, the performances of a wireless device placed in vicinity of the body may change compared to the exposure scenario without textile [5], [28].

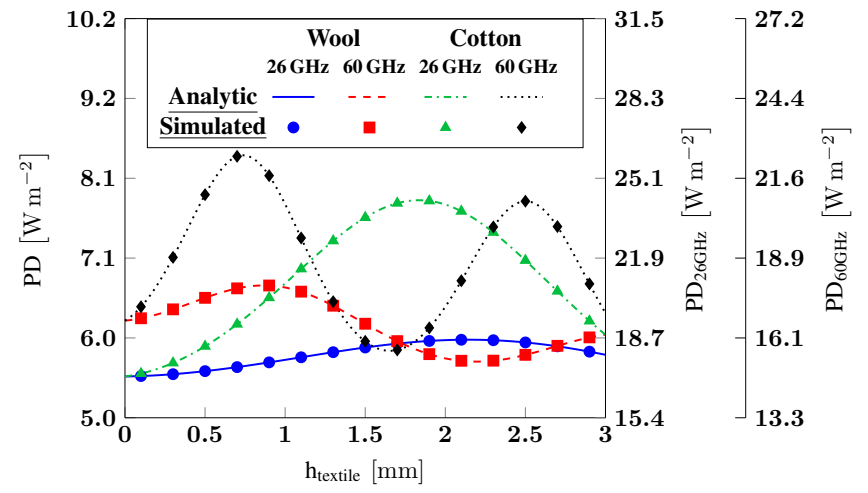

Figure 4: Absorbed power density in presence of a textile layer in contact with skin. The left y axis refers to the frequencyindependent IPD limits, while the two y axis on the right refer to the IPD frequency-dependent limits.

\section{B. Absorbed Power Density}

Figure 4 shows the PD in presence of a textile in contact with skin. As for the power transmission coefficient, PD increases in presence of the textile and shows an oscillatory behavior as a function of the textile thickness. The maximal PD is observed for a cotton layer with a thickness close to $\lambda / 4$ at $60 \mathrm{GHz}$ (34.4\% increase compared to the case without textile). At $60 \mathrm{GHz}$, two local maxima appear for cotton close to $h_{\text {textile }}=\lambda / 4$ and $h_{\text {textile }}=3 / 4 \lambda$. While for these 


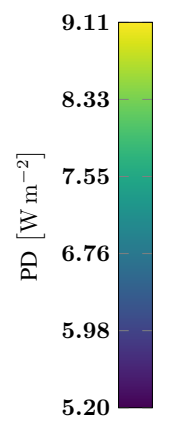

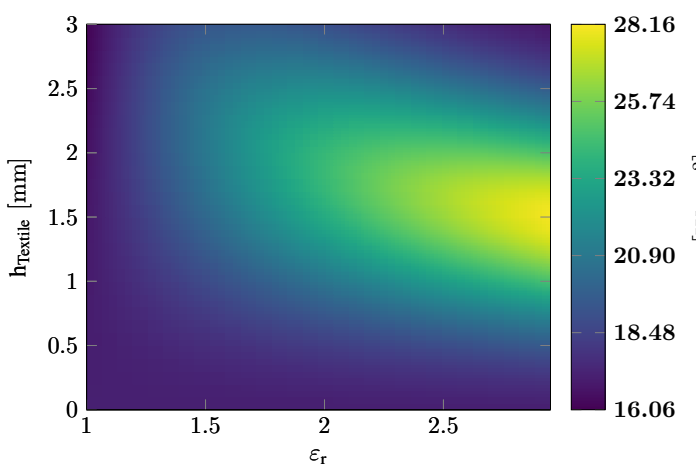

(a)

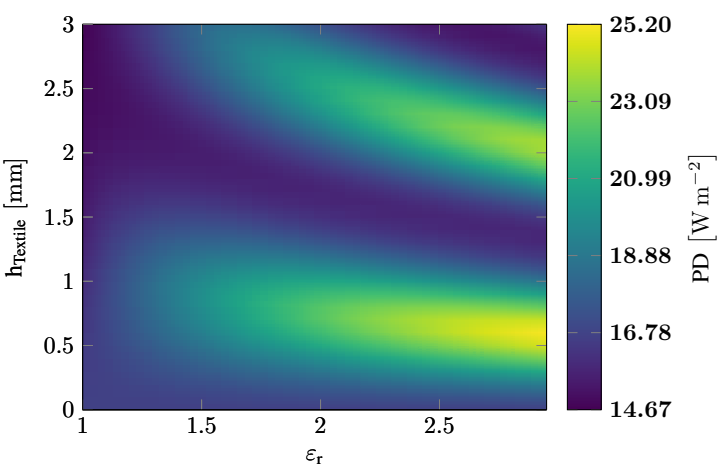

(b)

Figure 5: Absorbed power density as a function of the textile thickness and real permittivity $\varepsilon_{r}$ (a) at $26 \mathrm{GHz}$ and (b) at $60 \mathrm{GHz}$. The left and right colorbars refer to the frequency-independent and frequency-dependent limits of IPD, respectively.

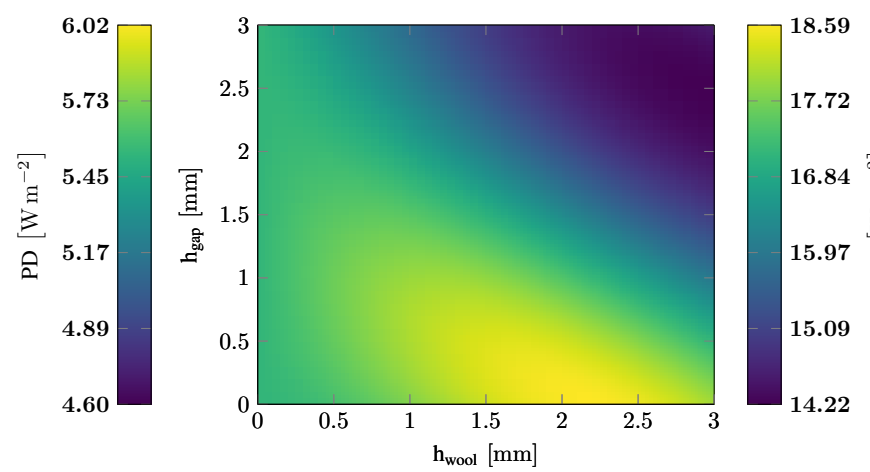

(a)
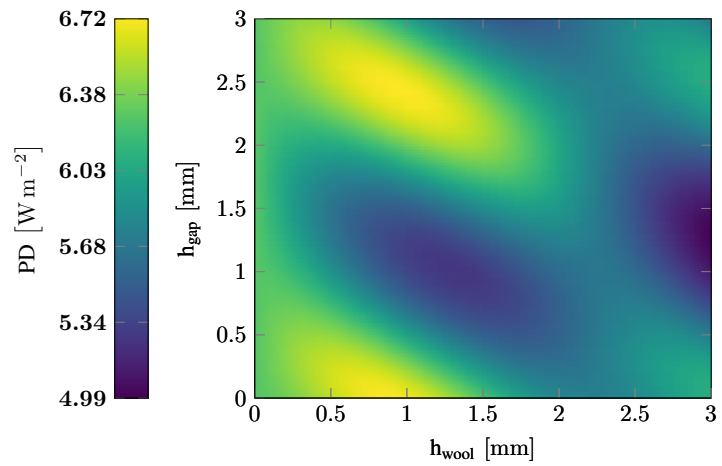

(c)
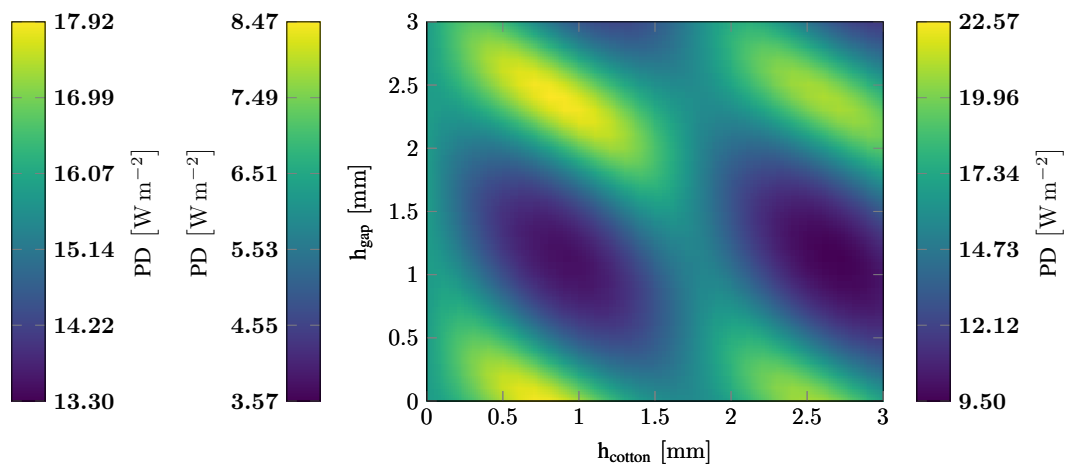

(d)

Figure 6: Absorbed power density at $26 \mathrm{GHz}$ ((a) wool and (b) cotton) and $60 \mathrm{GHz}$ ((c) wool and (d) cotton). The left and right colorbars on the left side refer to the frequency-independent and frequency-dependent limits of IPD, respectively.

two thicknesses the power transmission coefficient is almost the same, the corresponding PD decreases when the textile thickness increases. This can be attributed to higher losses in textile for $h_{\text {textile }}=3 / 4 \lambda$. At $26 \mathrm{GHz}$, the highest PD is observed for $1.84 \mathrm{~mm}$ thick cotton $\left(7.83 \mathrm{~W} \mathrm{~m}^{-2}\right.$ for $I P D=$ $10 \mathrm{~W} \mathrm{~m}^{-2}$ and $24.20 \mathrm{~W} \mathrm{~m}^{-2}$ for $I P D=30.90 \mathrm{~W} \mathrm{~m}^{-2}$ ). At $60 \mathrm{GHz}$, the highest PD is for $0.74 \mathrm{~mm}$ thick cotton $\left(8.42 \mathrm{~W} \mathrm{~m}^{-2}\right.$ and $22.43 \mathrm{~W} \mathrm{~m}^{-2}$ for $I P D=10 \mathrm{~W} \mathrm{~m}^{-2}$ and $I P D=26.65 \mathrm{~W} \mathrm{~m}^{-2}$, respectively). The slightly higher value at $26 \mathrm{GHz}$ than at $60 \mathrm{GHz}$ when considering frequency- dependent limits is due to the fact that at $26 \mathrm{GHz}$ the IPD limit is more elevated and losses in the textile are inferior at lower frequencies.

To consider other possible textile materials, the real part of the textile permittivity was varied in the $1-3$ range. The imaginary part was kept equal to that of wool. The resulting $\mathrm{PD}$ at $26 \mathrm{GHz}$ and $60 \mathrm{GHz}$ are represented in Figure 5. At both frequencies, the maximum PD is at $\varepsilon_{r}=3$ and is equal to $9.11 \mathrm{~W} \mathrm{~m}^{-2}$ (for $h_{\text {textile }}=1.49 \mathrm{~mm}$ ) and to $9.46 \mathrm{~W} \mathrm{~m}^{-2}$ (for $h_{\text {textile }}=0.58 \mathrm{~mm}$ ) at $26 \mathrm{GHz}$ and $60 \mathrm{GHz}$, respectively, for

\section{ACCEPTED MANUSCRIPT}


$I P D=10 \mathrm{~W} \mathrm{~m}^{-2}$. Considering the frequency-dependent limits, the highest PD is $28.16 \mathrm{~W} \mathrm{~m}^{-2}$ at $26 \mathrm{GHz}$ and $25.20 \mathrm{~W} \mathrm{~m}^{-2}$ at $60 \mathrm{GHz}$. As it was previously observed, at $60 \mathrm{GHz}$, due to increased electrical size of the textile compared to $26 \mathrm{GHz}$, two local maxima appear.

When accounting for an air gap between the textile and skin, the maximum PD does not occur at $h_{\text {textile }}=(2 n+1) \lambda / 4$ anymore, and depends on the air gap thickness (Figure 6). Considering the frequency-independent IPD limits, the maximum PD is $6.02 \mathrm{~W} \mathrm{~m}^{-2}$ for the wool and $7.83 \mathrm{~W} \mathrm{~m}^{-2}$ for the cotton at $26 \mathrm{GHz}$, while at $60 \mathrm{GHz}$ it reaches $6.73 \mathrm{~W} \mathrm{~m}^{-2}$ and $8.47 \mathrm{~W} \mathrm{~m}^{-2}$ for the wool and the cotton, respectively. These values are comparable to the maximum PD obtained for the configuration without an air gap between skin and textile.

\section{Heating}

To evaluate the heating, the steady-state temperature rise inside the skin layer, reached after roughly $30-40 \mathrm{~min}$ of exposure, was calculated. This represents the worst case scenario, and the temperature rise during the transient heating is expected to be lower. Figure $7 \mathrm{a}$ shows the temperature rise without an air gap as a function of the textile thickness. Presence of a textile in contact with skin increases heating. The highest temperature rise occurs for a textile thickness close to $(2 n+1) \lambda / 4$. Contrary to the trend of $\mathrm{PD}$, the temperature increase at $60 \mathrm{GHz}$ is higher for $h_{\text {cotton }}=3 / 4 \lambda$, compared to $h_{\text {cotton }}=\lambda / 4$. In fact, a thicker textile reduces the thermal exchange between skin and air. The maximal temperature increase at steady-state, corresponding to these two configurations for the frequency-independent limits, is $0.21^{\circ} \mathrm{C}$ at $26 \mathrm{GHz}$ and $0.24^{\circ} \mathrm{C}$ at $60 \mathrm{GHz}$, while for frequencydependent limits it reaches $0.66^{\circ} \mathrm{C}$ and $0.64^{\circ} \mathrm{C}$ at $26 \mathrm{GHz}$ and $60 \mathrm{GHz}$, respectively. Therefore the heating is up to $52 \%$ and $46 \%$ higher in presence of a textile at $26 \mathrm{GHz}$ and $60 \mathrm{GHz}$, respectively.

With an air gap, the temperature was calculated for the textile thickness corresponding to the typical values, i.e. $0.2 \mathrm{~mm}$ for cotton and $2 \mathrm{~mm}$ for wool (Figure $7 \mathrm{~b}$ ). In this case the maximum temperature rise at $26 \mathrm{GHz}$ is $0.17^{\circ} \mathrm{C}$ for $I P D=10 \mathrm{~W} \mathrm{~m}^{-2}$ and $0.52^{\circ} \mathrm{C}$ for $I P D=30.90 \mathrm{~W} \mathrm{~m}^{-2}$. At $60 \mathrm{GHz}$ the highest temperature increase is $0.2^{\circ} \mathrm{C}$ for $\mathrm{IPD}=10 \mathrm{~W} \mathrm{~m}^{-2}$ and $0.53^{\circ} \mathrm{C}$ for IPD $=26.65 \mathrm{~W} \mathrm{~m}^{-2}$.

\section{Discussion AND Conclusion}

We investigated and quantified the impact of a textile layer on the electromagnetic power deposition and resulting heating in a stratified near-surface tissue model. In continuation to the previous studies [13]-[15], this work provides an insight into the PD variation and resulting heating, which are two fundamental parameters to evaluate the exposure above $6 \mathrm{GHz}$. A normally impinging plane wave was considered as a source. Note that an oblique incidence would result in a lower PD and temperature elevation [29]. Aiming at the worst case condition, the temperature elevation was investigated at steady-state. Our results show that the presence of a textile in direct contact with skin increases the absorbed power density up to $41.5 \%$ at $26 \mathrm{GHz}$ and $34.4 \%$ at $60 \mathrm{GHz}$. This is due to the fact that

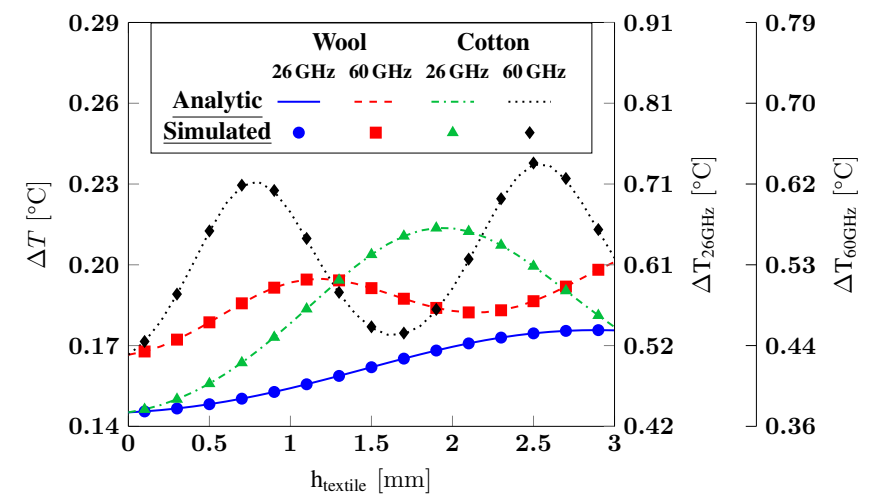

(a)

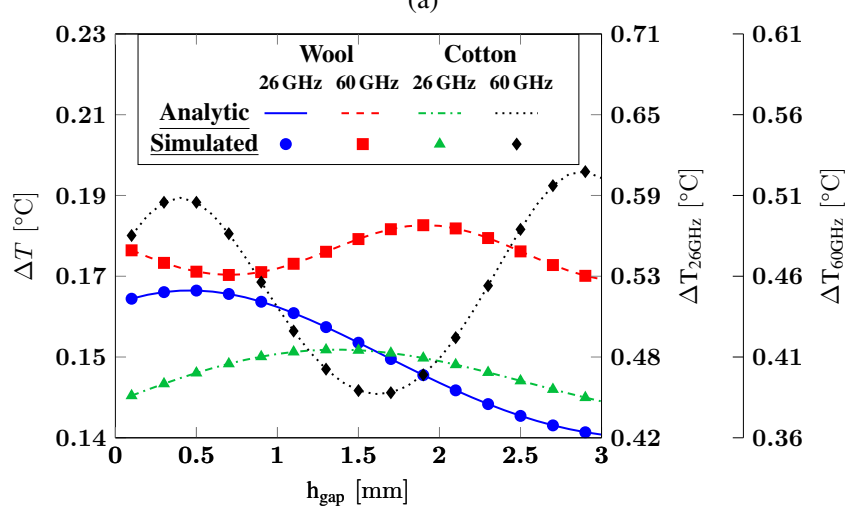

(b)

Figure 7: Maximal steady-state temperature elevation in the skin layer at $26 \mathrm{GHz}$ and $60 \mathrm{GHz}$ (a) as a function of the textile layer thickness (wool or cotton) for $h_{g a p}=0 \mathrm{~mm}$ and (b) as a function of the air gap thickness for $h_{w o o l}=2 \mathrm{~mm}$ and $h_{\text {cotton }}=0.2 \mathrm{~mm}$. The left y axis refers to the frequencyindependent IPD limits, while the two y axis on the right refer to the IPD frequency-dependent limits.

it plays a role of a matching layer. The presence of an air gap between the textile and skin can decrease or increase the electromagnetic power deposition in the tissues depending on the air gap and textile thicknesses, and on the textile complex permittivity. Without an air gap between a textile and skin, the temperature rise increases compared to the bare skin (up to $52 \%$ at $26 \mathrm{GHz}$ and $46 \%$ at $60 \mathrm{GHz}$ ). With an air gap and for the typical textile thicknesses, it ranges from $-3.5 \%$ to $20.6 \%$ and from $-11.1 \%$ to $20.9 \%$ at $26 \mathrm{GHz}$ and $60 \mathrm{GHz}$, respectively. When considering the available bandwidths for $5 \mathrm{G}$ applications, i.e. $24.25 \mathrm{GHz}-29.5 \mathrm{GHz}$ (including n257, $\mathrm{n} 258$, and $\mathrm{n} 261$ bands) [30] and the $57 \mathrm{GHz}-66 \mathrm{GHz}$ band [31], the maximal PD in presence of a textile varies by at most $3.2 \%$ and $9.9 \%$, respectively. These variations are of the same order of magnitude as the typical inter-individual variations. Validation of these conclusions using more realistic models constitutes one of the perspectives of this study.

\section{ACKNOWLEDGMENT}

The work was supported by the French National Research Program for Environmental and Occupational Health of ANSES (2018/2 RF/07) through NEAR 5G project. 
The authors would like to thank Zain Haider for proofreading the manuscript.

\section{REFERENCES}

[1] "High five," Nature Electronics, vol. 3, no. 1, pp. 1-1, Jan. 2020.

[2] T. S. Rappaport, Shu Sun, R. Mayzus, Hang Zhao, Y. Azar, K. Wang, G. N. Wong, J. K. Schulz, M. Samimi, and F. Gutierrez, "Millimeter wave mobile communications for $5 \mathrm{G}$ cellular: It will work!" IEEE Access, vol. 1, pp. 335-349, 2013.

[3] International Commission on Non-Ionizing Radiation Protection (ICNIRP), "Guidelines for limiting exposure to electromagnetic fields (100 kHz to $300 \mathrm{GHz}$ )," Health Physics, vol. 118, no. 5, pp. 483-524, May 2020.

[4] International Electrical and Electronics Engineers (IEEE), "IEEE standard for safety levels with respect to human exposure to electric, magnetic, and electromagnetic fields, $0 \mathrm{~Hz}$ to $300 \mathrm{GHz}$," 2019.

[5] A. R. Guraliuc, M. Zhadobov, R. Sauleau, L. Marnat, and L. Dussopt, "Near-field user exposure in forthcoming $5 \mathrm{G}$ scenarios in the $60 \mathrm{GHz}$ band," IEEE Transactions on Antennas and Propagation, vol. 65, no. 12, pp. 6606-6615, Dec. 2017.

[6] S. Kodera, J. Gomez-Tames, and A. Hirata, "Temperature elevation in the human brain and skin with thermoregulation during exposure to RF energy," BioMedical Engineering OnLine, vol. 17, no. 1, p. 1, Dec. 2018.

[7] G. Piro, P. Bia, G. Boggia, D. Caratelli, L. Grieco, and L. Mescia, "Terahertz electromagnetic field propagation in human tissues: A study on communication capabilities," Nano Communication Networks, vol. 10, pp. 51-59, Dec. 2016.

[8] L. Mescia, P. Bia, M. Chiapperino, and D. Caratelli, "Fractional Calculus Based FDTD Modeling of Layered Biological Media Exposure to Wideband Electromagnetic Pulses," Electronics, vol. 6, no. 4, p. 106, Nov. 2017.

[9] A. Christ, T. Samaras, E. Neufeld, and N. Kuster, "RF-induced temperature incerase in a stratified model of the skin for plane-wave exposure at 6-100 GHz," Radiation Protection Dosimetry, vol. 188, no. 3, pp. 350-360, Jun. 2020.

[10] K. Sasaki, M. Mizuno, K. Wake, and S. Watanabe, "Monte Carlo simulations of skin exposure to electromagnetic field from $10 \mathrm{GHz}$ to 1 THz," Physics in Medicine \& Biology, vol. 62, no. 17, pp. 6993-7010, Aug. 2017.

[11] M. C. Ziskin, S. I. Alekseev, K. R. Foster, and Q. Balzano, "Tissue models for RF exposure evaluation at frequencies above $6 \mathrm{GHz}$," Bioelectromagnetics, vol. 39, no. 3, pp. 173-189, Apr. 2018.

[12] M. Zhadobov, N. Chahat, R. Sauleau, C. Le Quement, and Y. Le Drean, "Millimeter-wave interactions with the human body: State of knowledge and recent advances," International Journal of Microwave and Wireless Technologies, vol. 3, no. 2, pp. 237-247, Apr. 2011.

[13] A. R. Guraliuc, M. Zhadobov, G. Valerio, and R. Sauleau, "Enhancement of on-body propagation at $60 \mathrm{GHz}$ using electro textiles," IEEE Antennas and Wireless Propagation Letters, vol. 13, pp. 603-606, 2014.

[14] A. R. Guraliuc, M. Zhadobov, G. Valerio, N. Chahat, and R. Sauleau, "Effect of textile on the propagation along the body at $60 \mathrm{GHz}$," IEEE Transactions on Antennas and Propagation, vol. 62, no. 3, pp. 14891494, Mar. 2014.

[15] O. Gandhi and A. Riazi, "Absorption of millimeter waves by human beings and its biological implications," IEEE Transactions on Microwave Theory and Techniques, vol. 34, no. 2, pp. 228-235, Feb. 1986.

[16] P. Chitrphiromsri and A. V. Kuznetsov, "Modeling heat and moisture transport in firefighter protective clothing during flash fire exposure," Heat and Mass Transfer, vol. -1, no. 1, pp. 1-1, Jun. 2003.

[17] C. Gabriel, "Compilation of the dielectric properties of body tissues at RF and microwave frequencies." Defense Technical Information Center, Fort Belvoir, VA, Tech. Rep., Jan. 1996.

[18] J. Luo, Y. Shao, X. Liao, J. Liu, and J. Zhang, "Complex permittivity estimation for cloths based on QPSO method over 40-50 GHz," IEEE Transactions on Antennas and Propagation, pp. 1-1, 2020.

[19] N. Rezgui, N. Bowring, Z. Luklinska, S. Harmer, and G. Ren, "Determination of the complex permittivity of textiles and leather in the 14-40 GHz millimetre-wave band using a free-wave transmittance only method," IET Microwaves, Antennas \& Propagation, vol. 2, no. 6, pp. 606-614, Sep. 2008.

[20] ITIS Foundation, "Database of Tissue Properties [Online]."

[21] W. E. Morton and J. W. S. Hearle, Physical Properties of Textile Fibres, 4th ed., ser. Woodhead Publishing in Textiles. Boca Raton, Fla.: CRC Press [u.a.], 2008, no. 68.
[22] D. Romeli, G. Barigozzi, S. Esposito, G. Rosace, and G. Salesi, "High sensitivity measurements of thermal properties of textile fabrics," Polymer Testing, vol. 32, no. 6, pp. 1029-1036, Sep. 2013.

[23] G. Havenith, K. Kuklane, J. Fan, and S. Hodder, "A database of static clothing thermal insulation and vapor permeability values of non-western ensembles for use in ASHRAE Standard 55, ISO 7730, and ISO 9920," ASHRAE Trans, vol. 121, p. 20, 2015.

[24] S. He, D. Huang, Z. Qi, H. Yang, Y. Hu, and H. Zhang, "The effect of air gap thickness on heat transfer in firefighters' protective clothing under conditions of short exposure to heat," Heat Transfer Research, vol. 43, no. 8, pp. 749-765, 2012.

[25] G. Song, S. Mandal, and M. Rossi, Thermal Protective Clothing for Firefighters, 2016.

[26] W. Kannuluik and E. Carman, "The temperature dependence of the thermal conductivity of air," Australian Journal of Chemistry, vol. 4, no. 3 , p. $305,1951$.

[27] J. P. Holman, Heat Transfer, Tenth Edition, 10th ed. New York: McGraw-Hill, 2010.

[28] M. Ziane, R. Sauleau, and M. Zhadobov, "Antenna/Body Coupling in the Near-Field at $60 \mathrm{GHz}$ : Impact on the Absorbed Power Density," Applied Sciences, vol. 10, no. 21, p. 7392, Oct. 2020.

[29] K. Li, K. Sasaki, S. Watanabe, and H. Shirai, "Relationship between power density and surface temperature elevation for human skin exposure to electromagnetic waves with oblique incidence angle from $6 \mathrm{GHz}$ to $1 \mathrm{THz}, "$ Physics in Medicine \& Biology, vol. 64, no. 6, p. 065016, Mar. 2019.

[30] European Telecommunications Standards Institute (ETSI), "5G; NR; User Equipment (UE) radio transmission and reception; Part 2: Range 2 Standalone (3GPP TS 38.101-2 version 15.3.0 Release 15)," Oct. 2018.

[31] European Telecommunications Standards Institute (ETSI), "MultipleGigabit/s radio equipment operating in the $60 \mathrm{GHz}$ band; Harmonised Standard covering the essential requirements of article 3.2 of Directive 2014/53/EU,’ Jul. 2017. 